\title{
The Positron Probe Microanalyser Studies of Defect Distribution Induced by Machining of Copper, Iron and Titanium
}

\author{
Jerzy Dryzek $^{1} \cdot$ Shigehiro Nojiri $^{2} \cdot$ Masanori Fujinami $^{2} \cdot$ Ewa Dryzek $^{1} \cdot$ \\ Krzysztof Siemek ${ }^{1} \cdot$ Wacław Pachla ${ }^{3}$
}

Received: 2 May 2015/Accepted: 24 August 2015/Published online: 14 September 2015

(c) The Author(s) 2015. This article is published with open access at Springerlink.com

\begin{abstract}
We demonstrate the application of the new experimental technique: positron probe microanalyser for studies of the defect profiles induced by milling. Metal foils of $\mathrm{Cu}, \mathrm{Fe}$ and $\mathrm{Ti}$ were subjected to machining in a milling machine with different cutting speed. This technique revealed well-defined profiles of defects below the machined surface which was extended up to hundreds of micrometres. The extent of the profile depended on the metal and the cutting speed. The positron probe microanalyser allowed us to trace the evolution of the profile after annealing in different temperatures. Surprisingly, the high thermal stability of a few tens of micrometres thick layer adjacent to the machined surface was detected.
\end{abstract}

Keywords Positron probe microanalyser - Subsurface defects $\cdot$ Machining $\cdot$ Titanium $\cdot$ Copper $\cdot$ Iron

\section{Introduction}

Milling is a fundamental machining process widely used for shaping products by material removal. The quality of a machined surface defined by its surface integrity has a great impact on the functional performance of these products. Surface integrity includes mechanical properties and

Jerzy Dryzek

jerzy.dryzek@ifj.edu.pl

1 Institute of Nuclear Physics, Polish Academy of Sciences, ul. Radzikowskiego 152, 31-342 Kraków, Poland

2 Department of Applied Chemistry, Chiba University, 1-33 Yayoi, Inage, Chiba 263-8522, Japan

3 Institute of High Pressure Physics, Polish Academy of Sciences, ul. Sokołowska 29/37, 01-142 Warsaw, Poland the actual structure of both surface and subsurface. The first of two aspects of surface integrity concerns mainly surface topography and the second subsurface layer. The subsurface layer sustains severe plastic deformation, when machining, which together with temperature induced by friction causes alteration of microstructure and residual stresses in the subsurface of a machined component. Influence of cutting methods and conditions on different elements of surface integrity such as residual stresses, surface roughness, microhardness and changes of microstructure have been extensively studied. The review of results can be found for instance in Refs. [1-3].

As it was reported, machining operations generate large strains and strain gradients in the work material. The deformation microstructure of copper subjected to orthogonal cutting was studied by Elmadagli and Alpas [4]. Metallographic analysis and microhardness mapping of the chip root specimens allowed the authors to determine the local strain gradients and flow stress variations in the deformed material ahead of the tool tip. The plastically deformed zone extended to a depth of about $300 \mu \mathrm{m}$ below the cutting line. Similar studies performed by $\mathrm{Ni}$ et al. [5] for 1100 aluminium subjected to dry machining reported the plastically deformed zone extended to a depth of about $1600 \mu \mathrm{m}$ below the cutting line.

Investigations of the deformation zones ahead of the tool tip as well as beneath the machined surfaces of austenitic steel AISI 304 performed by lino et al. [6] using subsequent recrystallization technique showed that the very high strain at the surface decreased very steeply to $\varepsilon \approx 0.5$ within a few tens of micrometres. Then, the strain decreased gradually. The depth at which $\varepsilon \approx 0.12$ was 100-200 $\mu \mathrm{m}$, and the depth of the plastically deformed zone, i.e., 200-450 $\mu \mathrm{m}$, increased with the increasing cut depth and rake angle. M'Saoubi and Ryde applied the 
electron back-scattering diffraction (EBSD) technique for studying deformation zones of iron, and single and twophase steels subjected to orthogonal cutting [7]. The results obtained from EBSD mapping of the layer beneath the machined surface and microhardness profiling indicated that iron displayed the deepest work-hardened area, c.a $700 \mu \mathrm{m}$ in comparison with investigated steels, i.e., up to $200 \mu \mathrm{m}$. The relative rotation of individual grains which accompanied large deformation was also found to be the largest in the case of iron.

Plastic deformation in the subsurface layer of a machined component, occurring via dislocation motion and interactions, produces also a defect profile extending beneath the machined surface which can be studied using positron annihilation methods. These methods are very sensitive to defects at atomic level and allow us to investigate changes induced by machining process more precisely than other methods used for material characterization [8]. Positron being an antiparticle to an electron due to its positive charge and thermal energy can be localized at open-volume defects. This is finally reflected in the measured positron annihilation characteristics and allows determining changes in the concentration of defects very accurately. This is quite useful for studies of defect distribution induced by different technological process like friction, cutting, welding and others. Positron annihilation methods were applied, for example, to study defects induced during cutting of materials important for semiconductor technology. In that case, defects can affect electronic properties of surface or subsurface of produced wafers of single crystals. Surface damage created by diamond saw cutting was studied for single crystal wafers of $\mathrm{Cd}_{1-x} \mathrm{Zn}_{x} \mathrm{Te}$ [9] and GaAs [10]. Horodek et al. [11] applied positron annihilation methods to compare the defect profiles beneath the surface of austenitic steel AISI 304 machined using different techniques, i.e., abrasive water jet cutting, laser cutting and milling. The obtained defect profiles differed essentially from each other. Laser beam cutting generated the subsurface layer with the lowest concentration of defects which did not vary with the depth up to $500 \mu \mathrm{m}$. In the case of milling, defect concentration was the highest at the surface and decreased with the increase in the depth beneath the machined surface. The defect profile was extended to the depth of $150 \mu \mathrm{m}$. The defects were mainly edge dislocations decorated by vacancies. Abrasive water jet cutting induced also a similar profile, but it was extended to a lower depth, i.e., $40 \mu \mathrm{m}$. Those defect profiles were obtained by successive removing of layers from the sample surface and measuring of positron annihilation characteristics. As it was shown recently, the new possibilities of profiling or mapping of defects are provided by the positron probe microanalyser (PPMA), see Refs. [12] and [13].
The potential use of PPMA for the investigation of deformed layer beneath the machined surface has been explored. The goal of this investigation was to use this technique, for studies of the subsurface layer induced by the machining process. Three different metals: $\mathrm{Fe}, \mathrm{Cu}$ and Ti, were cut by milling, and the subsurface region of the samples was scanned using the PPMA to obtain depth profiles of defects induced during machining and find out their dependence on the kind of metal and cutting speed. The samples were exposed to the annealing at different temperatures to observe an evaluation of the defect profile. The comparison of the PPMA results with those obtained by conventional measurements based on the etching technique is made as well.

\section{The Measurement Details}

\subsection{Sample Preparation}

Three metals: $\mathrm{Cu}, \mathrm{Fe}$ and $\mathrm{Ti}$, in the form of foils of thickness of $100 \mu \mathrm{m}$ and size of $1 \mathrm{~cm} \times 1 \mathrm{~cm}$ were selected for the presented investigation. Before machining, each foil was annealed at temperature of about $500{ }^{\circ} \mathrm{C}$ in the flow of $\mathrm{N}_{2}$ gas to remove defects. This process was important, because the foils contained defects induced during their manufacturing which can overlap defects induced by machining. The positron lifetime measurements revealed single lifetime component equal to 110,120 and $142 \mathrm{ps}$ for $\mathrm{Fe}, \mathrm{Cu}$ and $\mathrm{Ti}$, respectively. All these values correspond to the positron lifetime bulk values reported in the literature [14]. One additional sample of nanocrystalline Fe ARMCO foil with the mean crystallite size of about $100 \mathrm{~nm}$ was also prepared [15]. To perform milling, the foil was fixed between two aluminium bars of size of $1 \mathrm{~cm} \times 1 \mathrm{~cm}$ and $3 \mathrm{~cm}$ long. They ensured the annealed foils are not exposed to other mechanical handling, for instance bending. This sandwich was placed in a milling

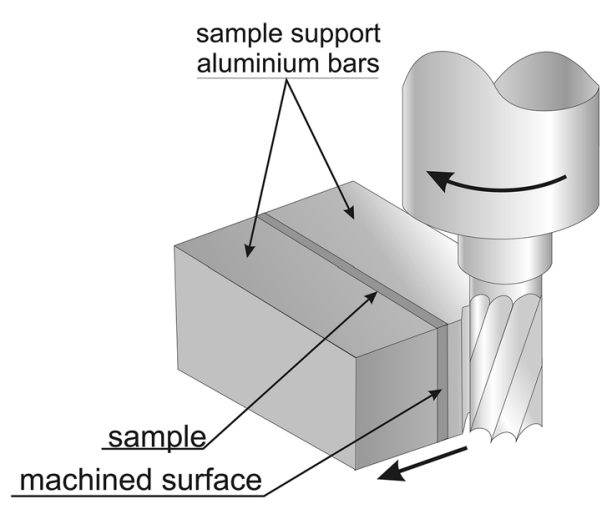

Fig. 1 Scheme of the foil cutting in the milling machine 
machine, and a rotating face cutter cut it in the direction perpendicular to the foil plane (see scheme in Fig. 1). Four rotating speeds were chosen, i.e., 380, 590, 945 and $1500 \mathrm{rpm}$, which correspond to the linear speed of the cutter against the cut surface of $12,19,30$ and $47 \mathrm{~m} / \mathrm{min}$. The feed rate was about $2 \mathrm{~mm} / \mathrm{s}$ and the depth of cut about $2 \mathrm{~mm}$. After that, the foil was mounted in the PPMA, and the region beneath the machined surface was scanned by the positron beam. The scheme of the measurement is depicted in Fig. 2.

\subsection{The PPMA Measurements}

In this device moderated ${ }^{22} \mathrm{Na}$ positrons are moderated, then accelerated to the energy of $24.5 \mathrm{keV}$ and formed in a beam using a special technique with the magnetic fields. The beam spot on the sample surface is about $20 \mu \mathrm{m}$ in diameter. Due to applied magnetic lenses, the sample must be in the form of a foil $100 \mu \mathrm{m}$ thick. The average depth below the entrance surface at which positrons are implanted is about $0.6 \mu \mathrm{m}$. In practice, only the spot of the beam limits the spatial distribution of positrons in the foil. The $\mathrm{Si}$ wafer constitutes a table which the foil is located. The foil with the table can be moved perpendicularly to the beam and the machined surface (Fig. 2). The HpGe detector located close to the table with the foil registers the annihilation photons of about $511 \mathrm{keV}$ as a function of the distance of the beam from the machined surface.

It is important to fix the zero position of the beam. The positron beam profile can be Gaussian-approximated, and the centre position of the beam is not the machined surface of the sample. If so, half of the data would stand for the

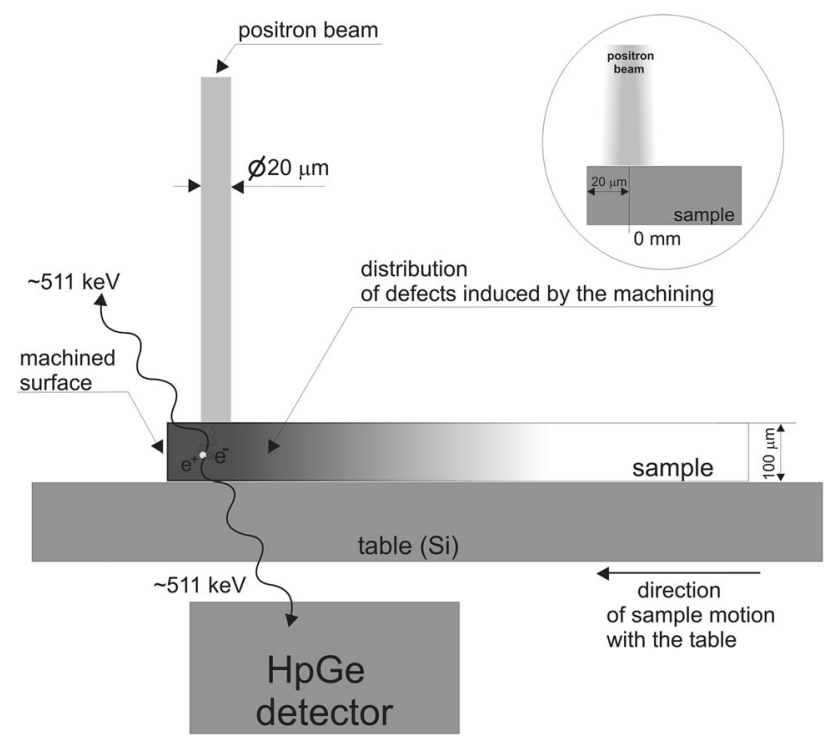

Fig. 2 Scheme of the PPMA measurement. The inset explains how the zero position of the positron beam is defined table not for the sample, and it have to be avoided. We measured the count rate of annihilation photons in order to confirm the whole positrons injected annihilate in the sample. If positrons are injected in the Si table, the count rate increases because the reflection efficiency decreases in low-mass-number material. Then, the centre of the positron beam is located at $20 \mu \mathrm{m}$ apart from the machined surface of the sample, see the inset in Fig. 2. This position defines the distance from the machined surface tagged in Figs. 3, 4 and 6. This distance can be treated as a depth, because in fact it is the depth from this surface if the sample is not a foil but a rod or bar.

Positrons injected into the foil are thermalized and after a random walk annihilate with electrons. The energy of two emitted annihilation photons depends on the momentum of the annihilating positron-electron pair but in practice on the momentum of the electron. Due to the positive charge, when random walking, the positron can be trapped at openvolume defects, which contain low-momentum electrons, and this is clearly visible in the Doppler-broadened annihilation line. The S-parameter commonly used for characterization of the annihilation line is defined as the integral of the central part of the annihilation line normalized to the total integral of the line centred at $511 \mathrm{keV}$. It has been demonstrated by many authors that this parameter is extremely sensitive to the presence of openvolume defects, such as vacancies, their clusters and dislocation lines, and jogs at dislocation lines, where positrons can be trapped and annihilate. More technical details about the PPMA constructed at the Chiba University in Japan were given in the papers by Fujinami et al. [16] and Oshima et al. [20].

The PPMA being a non-destructive technique allows us to take several measurements for the same sample. This is very convenient for studies of thermal stability of a defect profile created beneath the machined surface. The foils of $\mathrm{Cu}, \mathrm{Fe}$ and Ti machined with the highest cutting speed, i.e. $47 \mathrm{~m} / \mathrm{min}$, were successively annealed at temperatures of 200, 300, 400 and $500{ }^{\circ} \mathrm{C}$, during $1 \mathrm{~h}$ in Ar atmosphere, and then the measurements of the S-parameter as a function of the distance from the machined surface were taken.

\subsection{The Conventional Measurement with Successive Etching}

For this measurement, two samples of pure $\mathrm{Cu}$ in the shape of a rod of diameter 1 and $2 \mathrm{~cm}$ long were annealed at $500{ }^{\circ} \mathrm{C}$ during $1 \mathrm{~h}$ in the flow of $\mathrm{N}_{2}$ gas. The measurement of the positron lifetime revealed single lifetime component equal to $120 \mathrm{ps}$. It indicated that only residual defects were present in the samples. Then, the basal surfaces of the rods were machined. The cutting speed was $47 \mathrm{~m} / \mathrm{min}$, the feed rate was $2 \mathrm{~mm} / \mathrm{s}$, and the depth of cut was $2 \mathrm{~mm}$. The 
distance from the machined surface $(\mu \mathrm{m})$
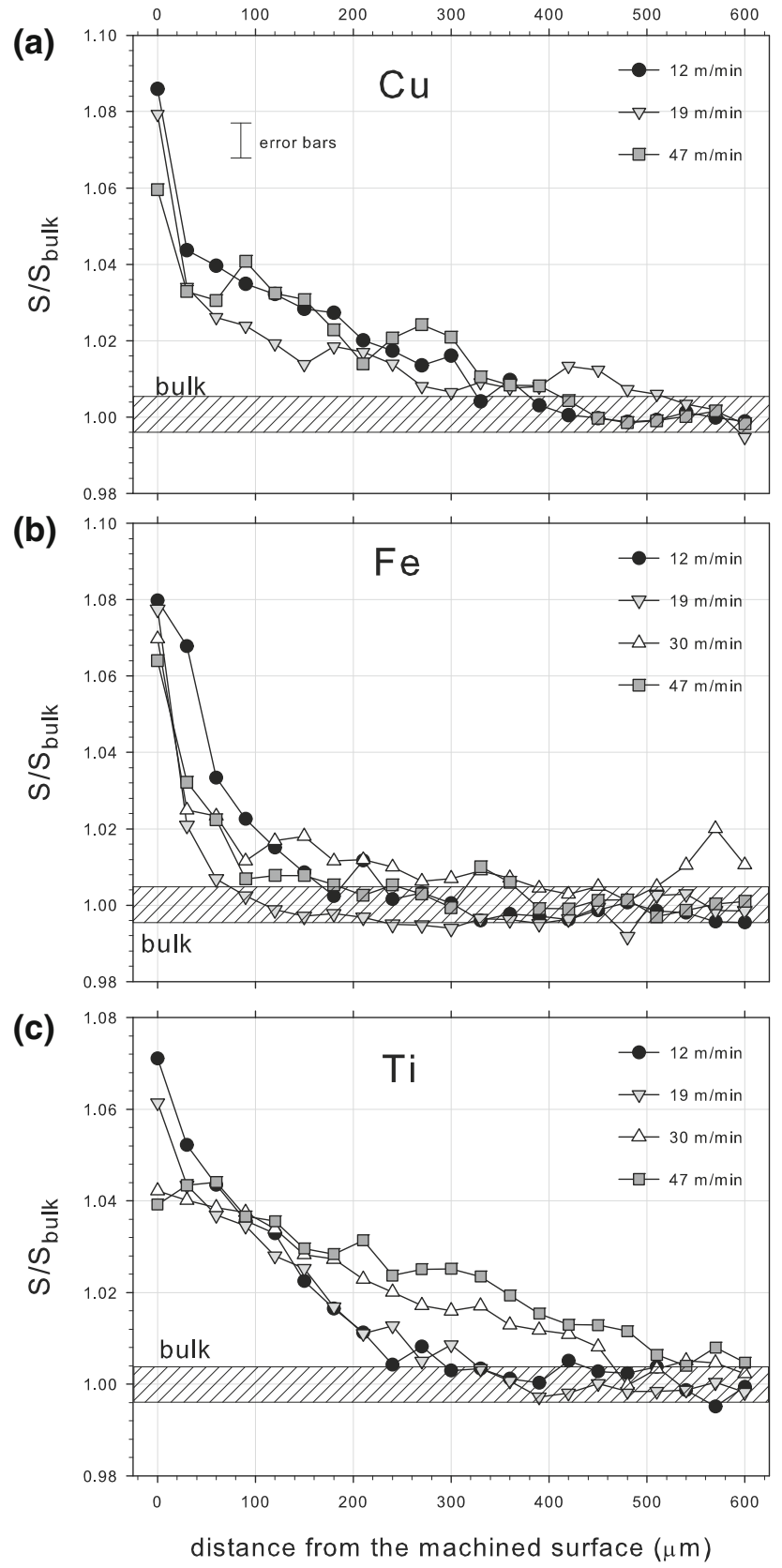

Fig. 3 Dependencies of the normalized S-parameter values on the distance, or depth from the machined surface for well-annealed foils of pure $\mathrm{Cu}(\mathbf{a}), \mathrm{Fe}(\mathbf{b})$ and $\mathrm{Ti}(\mathbf{c})$ in the milling machine with different cutting speeds. The measurements were taken using the PPMA

positron source of ${ }^{22} \mathrm{Na}$ was located between the machined surfaces of two samples, and such a sandwich was placed in front of the $\mathrm{HpGe}$ detector for measurement of the S-parameter. After that, the samples were etched in the solution of the nitric acid to remove a layer about $20 \mu \mathrm{m}$ thick from the machined surfaces of the samples. The reduction in the rod length was measured using a

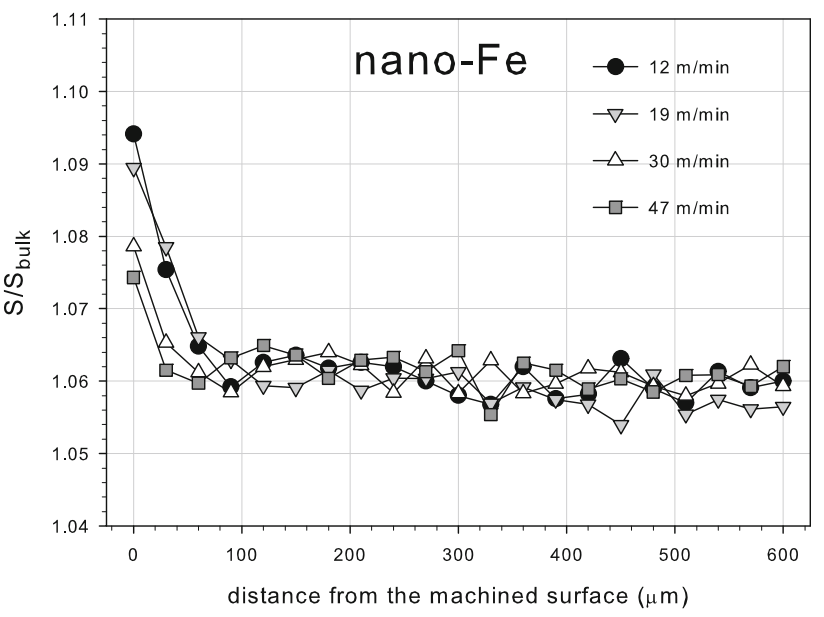

Fig. 4 Dependencies of the normalized S-parameter values on the distance or depth from the machined surface for nanocrystalline foil of pure Fe cut in a milling machine with different cutting speeds. The measurements were taken using the PPMA

micrometre screw, and half of this value is treated as a depth from the machined surface. Then, the measurement of the S-parameter was taken again. The successive etching allowed us to reveal the deeper layers beneath the machined surface. Such a procedure was repeated until bulk value of the $S$-parameter is achieved.

\section{Results and Discussion}

\subsection{Results of the PPMA Measurements}

The positron annihilation studies performed by Horodek et al. [11] indicated that concentration of defects generated by milling decreased with the increase in the depth from the machined surface. Figure 3 presents similar dependencies of the S-parameter on the depth beneath the machined surface for three well-annealed foils of $\mathrm{Cu}$, Ti and $\mathrm{Fe}$ and for four different cutting speeds obtained using the PPMA. All values of the S-parameter are normalized to the bulk value for each metal. It can be noticed that in each case, the highest value of the S-parameter is on the machined surface. Then, the value of the S-parameter decreases with the increasing distance from the machined surface (Fig. 2). At a certain distance, the bulk value tagged as the hatched area in Fig. 3 is reached. The extent of the measured profile depends on the metal and the cutting speed. For $\mathrm{Cu}$, this extent ranges from 260 to $500 \mu \mathrm{m}$ (Fig. 3a); for Ti, it is from 240 to $520 \mu \mathrm{m}$ (Fig. 3c), and for $\mathrm{Fe}$, the smaller extent is observed, i.e., from 80 to $260 \mu \mathrm{m}$ (Fig. 3b). The increase in the defect profile extent with the increasing cutting speed is clearly visible for Ti (Fig. 3c). For other two metals, this tendency is also noticeable. For 
$\mathrm{Ti}$ and $\mathrm{Cu}$, the value of the S-parameter on the machined surface decreases with the increase in the cutting speed. For $\mathrm{Fe}$, this tendency is less visible, because the differences between the $\mathrm{S}$-parameter values on the surface are smaller.

The S-parameter value for $\mathrm{Ti}$ and $\mathrm{Cu}$ decreases almost linearly with the increasing distance from the machined surface, while for the samples after dry sliding, the decrease in this parameter can be described by exponential or sigmoidal decay $[17,18]$. This may indicate that during machining, the formation of the deformed subsurface layer and generation of defect profile occurs in a different way than in the case of dry sliding. A good example is Ti. In this metal the subsurface zone created by dry sliding consists of two layers and the positron annihilation parameter corresponding to the S-parameter exhibits the characteristic plateau adjacent to the worn surface [18]. However, for milling, a plateau is not observed. Instead, the linear decrease is visible (Fig. 2c).

For dry sliding, the normal load can be high. During milling, mainly the shear stress contributes to the formation of the subsurface deformation. We argue that dislocations created at the machined surface are mainly responsible for the defect profile generation. The dislocations are accompanied by halos of interstitial atoms and vacancies. At room temperature, these defects due to the high mobility annihilate, but also vacancy clusters are formed, as it is, for instance, in $\mathrm{Ti}$ [18] or $\mathrm{Cu}$ [19]. The vacancy clusters are easily detected by positrons.

It is worth noticing that microhardness profiles measured for titanium-based alloys created by both turning and milling indicate a harder level on the surface of the machined material, which can lead to a work-hardening layer $[3,21]$. The extent of microhardness profiles for titanium alloys is comparable with the extent of defect profile for Ti reported in this paper. There are also reports that increasing the cutting speed created higher hardness values [22].

The formation of the defect profile in the subsurface in well-annealed, almost defects-free samples can be relatively easy. Dislocations created at the machined surface can almost freely move in the interior of the samples and can be stopped at other dislocations which have been generated there earlier. This can explain the large extent of the defect profiles reported above. However, the defect profile is formed also in the case of samples, which initially contains defects. It is demonstrated for the Fe ARMCO sample with nanosize grains. The milling procedure described above was applied to the foil of nanocrystalline Fe. In Fig. 4, the values of the S-parameter as a function of the distance from the machined surface are depicted. The defect profile is extended to the depth between 20 and $80 \mu \mathrm{m}$; thus, its range is much smaller in comparison with the well-annealed Fe foil (Fig. 2b). We argue that in this case, the grain boundaries and defects inside the grains are effective in blocking dislocation motion. At the distance above $100 \mu \mathrm{m}$, i.e., the region not affected by milling, positrons are trapped mainly at grain boundaries or defects in the interior of grains. The results for pure annealed $\mathrm{Fe}$ and nanocrystalline Fe correspond with the results reported in Ref. [7] mentioned above.

\subsection{Comparison of the PPMA with the Conventional Positron Technique}

The application of the PPMA to the studies of defect profiles is a new one. Therefore, the PPMA results are compared with the results obtained using other technique based on the successive etching of layers from the sample surface and measuring of positron annihilation characteristics reported in numerous papers. In Fig. 5, we depicted the dependency of the S-parameter on the distance from the machined surface obtained in this way for the $\mathrm{Cu}$ rod. It can be noticed that the extent of the profile is equal to ca. $300 \mu \mathrm{m}$, and it corresponds to the depth obtained by the PPMA. Also it is clearly visible that the S-parameter decreases linearly with the increase in the depth, excluding two points adjacent to the machined surface. This behaviour is similar to that presented in Fig. 3a for the $\mathrm{Cu}$ foil sample where the higher value of the S-parameter at the machined surface is also observed. It can be concluded that both measurements give almost identical results. Then, the PPMA can be recommended for studies of defect profiles created in the subsurface by different processes.

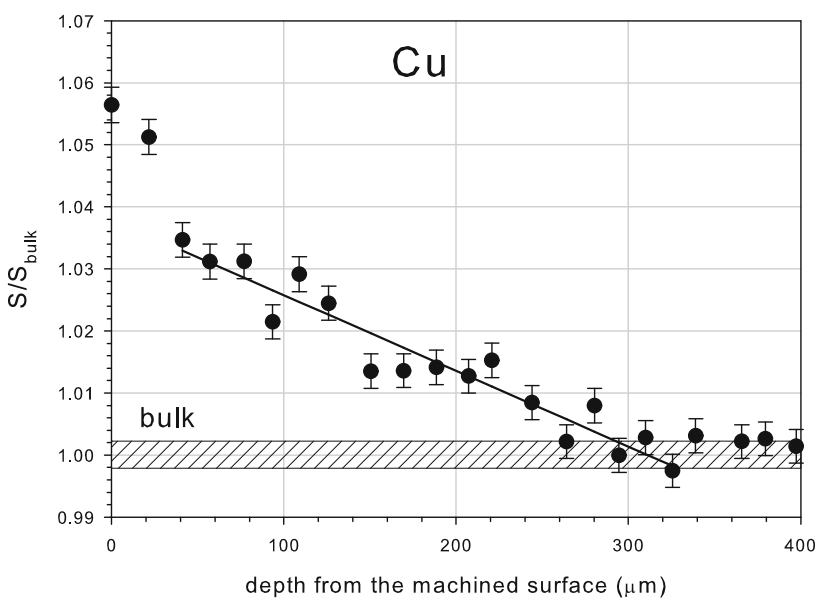

Fig. 5 Dependencies of the normalized S-parameter value on depth from the machined surface for the rod of well-annealed $\mathrm{Cu}$ cut in a milling machine. The cutting speed was equal to $47 \mathrm{~m} / \mathrm{min}$. The measurement was taken using the conventional technique with ${ }^{22} \mathrm{Na}$ positrons with the sequenced etching of the sample layers, see text 


\subsection{The Subsurface Zone After Annealing}

Defects induced during plastic deformation can be removed or rearranged in a configuration of lower energy after annealing at a sufficiently high temperature. Recovery and recrystallization are well-recognized processes in deformed metals exposed to annealing. Recrystallization annealing was reported as a method which allows revealing plastic zones with different amount of strain beneath the machined surface [6]. The general relationship between strain and the recrystallized grain size was obtained based on the tensile experiment. The zone with higher strain recrystallized at lower annealing temperature, and the distance from the machined surface to the zone front could be measured. Then, the annealing at higher temperatures was performed to obtain recrystallization of the zones with lower strains.

We performed the similar experiment for the foils of $\mathrm{Cu}$, $\mathrm{Fe}$ and Ti previously milled with the highest cutting speed, i.e., $47 \mathrm{~m} / \mathrm{min}$. Figure 6 presents the obtained dependencies of the S-parameter on the distance from the machined surface for the foils after annealing. For all foils, the value of the S-parameter at the machined surface decreases with the increasing annealing temperature, but the bulk value is not reached even after annealing at $500{ }^{\circ} \mathrm{C}$. It should be emphasized that such a temperature is sufficient for removal of defects induced by plastic deformation in compression. In that case, the S-parameter at the surface decreases to the bulk value after annealing [23]. In the present case for $\mathrm{Cu}$, defects remain in the layer adjacent to the surface even after annealing at $400{ }^{\circ} \mathrm{C}$. The extent of the profile diminishes from 400 to $100 \mu \mathrm{m}$. In deeper layers, the S-parameter gradually decreases with the increasing annealing temperature, indicating that after annealing at $400{ }^{\circ} \mathrm{C}$, the defects are removed. This confirms the high thermal stability of the layer adjacent to the machined surface. The similar behaviour is clearly visible also for Ti (Fig. 6c). The extent of the profile decreases from 550- to 50- $\mu \mathrm{m}$ Ti (Fig. 6a, c). It indicates that in the deeper layers, the removal of defects and creation of new defect-free grains take places with the increasing annealing temperature. It should be noted that such a behaviour is slightly different from that observed in the case of dry sliding, where after annealing at $400{ }^{\circ} \mathrm{C}$, a maximum in the profile occurs at the depth of about $80 \mu \mathrm{m}$ from the worn surface [23]. The maximum indicates the creation of new open-volume defects, like vacancy clusters; presumably they occur due to the dislocation motion release at higher temperature [24]. For Fe, the dependencies of the S-parameter depicted in Fig. $6 \mathrm{~b}$ show that there are no visible changes in the defect profiles after annealing except the decrease in the S-parameter at the surface. It indicates that the annealing temperatures in case of $\mathrm{Fe}$ are too low to cause changes in the defect structure of the subsurface. distance from the machined surface $(\mu \mathrm{m})$
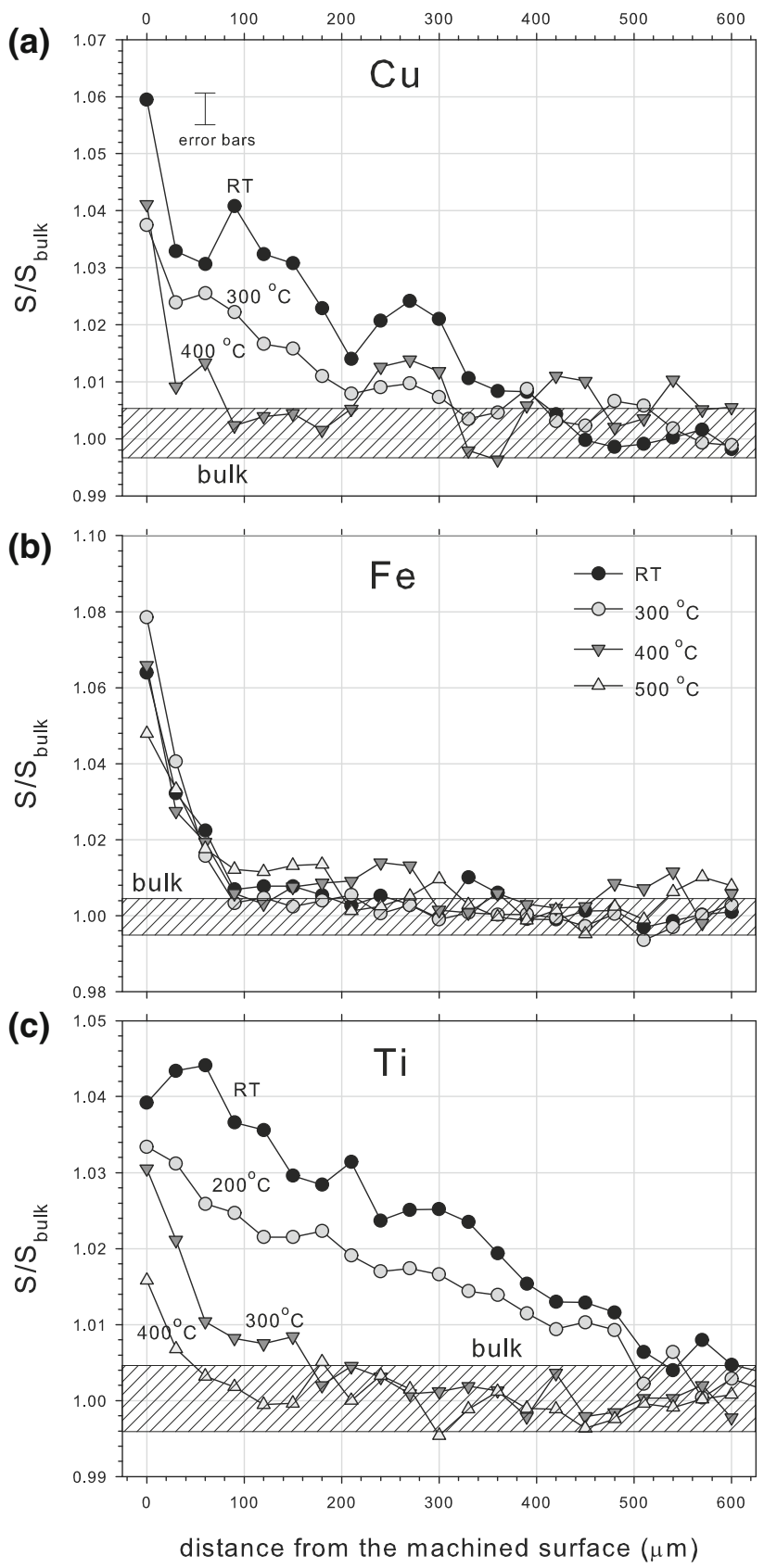

Fig. 6 Dependencies of the normalized S-parameter value on the distance or depth from the machined surface for well-annealed foils of pure $\mathrm{Cu}(\mathbf{a}), \mathrm{Fe}(\mathbf{b})$ and $\mathrm{Ti}(\mathbf{c})$, for the cutting speed $47 \mathrm{~m} / \mathrm{min}(R T$ room temperature). After machining, the foils were subsequently annealed at temperatures: $200,300,400$ and $500{ }^{\circ} \mathrm{C}$. The measurements were taken using PPMA

\section{Conclusions}

Application of the PPMA revealed the well-defined defect profiles generated during milling of foils of three annealed metals: $\mathrm{Cu}, \mathrm{Fe}$ and $\mathrm{Ti}$ with different cutting speeds. The 
highest concentration of defects is observed in the region adjacent to the machined surface, and then, the defect concentration gradually decreases with the increasing depth. The extent of the defect profiles depends on the kind of metal and the cutting speed. For Ti and the cutting speed of $47 \mathrm{~m} / \mathrm{min}$ it is the largest one, i.e., about $520 \mu \mathrm{m}$. The smaller extend of the defect profile, i.e., about $80 \mu \mathrm{m}$ is observed for $\mathrm{Fe}$ for the cutting speed of $19 \mathrm{~m} / \mathrm{min}$. These data correspond with the data reported by other authors who studied the subsurface deformation using, for instance, microhardness measurements. After annealing of $\mathrm{Cu}$ and $\mathrm{Ti}$ foils, the defects are removed gradually with increasing annealing temperature in the deeper regions which may be caused by recovery process. However, in a few tens of micrometres thick layer adjacent to the machined surface, the defects remain, but their concentration decreases. This shows the high thermal stability of this layer.

Open Access This article is distributed under the terms of the Creative Commons Attribution 4.0 International License (http://crea tivecommons.org/licenses/by/4.0/), which permits unrestricted use, distribution, and reproduction in any medium, provided you give appropriate credit to the original author(s) and the source, provide a link to the Creative Commons license, and indicate if changes were made.

\section{References}

1. Davim, J.P. (ed.): Surface integrity in machining. Springer, London (2010)

2. Jawahir, I.S., Brinksmeier, E., M'Saoubi, R., Aspinwall, D.K., Outeiro, J.C., Meyer, D., Umbrello, D., Jayal, A.D.: Surface integrity in material removal processes: recent advances. CIRP Ann. Manuf. Technol. 60, 603-626 (2011)

3. Ulutan, D., Tugrul, O.: Machining induced surface integrity in titanium and nickel alloys: a review. Int. J. Mach. Tools Manuf. 51, 250-280 (2011)

4. Elmadagli, M., Alpas, A.T.: Metallographic analysis of the deformation microstructure of copper subjected to orthogonal cutting. Mater. Sci. Eng. A 355, 249-259 (2003)

5. Ni, H., Elmadagli, M., Alpas, A.T.: Mechanical properties and microstructures of 1100 aluminum subjected to dry machining. Mater. Sci. Eng. A 385, 267-278 (2004)

6. Iino, Y., Kim, T.Y., Mun, S.D.: Machined surface plastic strain in orthogonal cutting by subsequent recrystallization technique. Wear 199, 211-216 (1996)

7. M'Saoubi, R., Ryde, L.: Application of the EBSD technique for the characterisation of deformation zones in metal cutting. Mater. Sci. Eng. A 405, 339-349 (2005)
8. Krause-Rehberg, R., Leipner, H.S.: Positron annihilation in semiconductors: defect studies. Springer, Berlin (1999)

9. McNeil, S., Lynn, K., Weber, M., Szeles, C., Soundararajan, R.: Positron-defect profiling in $\mathrm{Cd}_{1-x} \mathrm{Zn}_{x} \mathrm{Te}$ wafers after saw cutting. J. Electron. Mater. 29, 583-585 (2003)

10. Börner, F., Eichler, S., Polity, A., Krause-Rehberg, R.: Determination of the defect depth profile after saw cutting of GaAs wafers measured by positron annihilation. J. Appl. Phys. 84, 2255-2262 (1998)

11. Horodek, P., Dryzek, J., Wróbel, M.: Positron annihilation study of defects induced by various cutting methods in stainless steel grade 304. Tribol. Lett. 45, 341-347 (2012)

12. Dryzek, J., Nojiri, S., Fujinami, M.: The positron microscopy studies of the wear tracks on the copper surface. Tribol. Lett. 56, 101-106 (2014)

13. Coleman, P.G.: Positron beams and their applications. World Scientific, Singapore (2000)

14. Robles Campillo, J.M., Ogando, E., Plazaola, F.J.: Positron lifetime calculation for the elements of the periodic table. J. Phys. Condens. Matter 19, 176222 (2007)

15. Kulczyk, M., Pachla, W., Świderska-Środa, A., Suś-Ryszkowska, M., Mazur, A., Kurzydłowski, K.J.: Nano- and ultra-fine grained structures in iron and nickel induced by hydrostatic extrusion. In: Proceedings of The 9th International ESA-FORM Conference on Material Forming, University of Strathclyde, Glasgow, UK, April 26-28, 2006 (2006)

16. Fujinami, M., Jinno, S., Fukuzumi, M., Kawaguchi, T., Oguma, K., Akahane, T.: Production of a positron microprobe using a transmission remoderator. Anal. Sci. 24, 73-79 (2008)

17. Dryzek, J., Dryzek, E., Stegemann, T., Cleff, B.: Positron annihilation studies of subsurface zones in copper. Tribol. Lett. 3, 269-275 (1997)

18. Dryzek, J., Wróbel, M.: Positron studies of subsurface zone in titanium created in sliding wear. Tribol. Lett. 55, 413-419 (2014)

19. Dryzek, J., Polak, A.: Subsurface zone studied by positron lifetime measurements. Tribol. Lett. 7, 57-60 (1999)

20. Oshima, N., Suzuki, R., Ohdaira, T., Kinomura, A., Narumi, T., Uedono, A., Fujinami, M.: Brightness enhancement method for a high-intensity positron beam produced by an accelerator. J. Appl. Phys. 103, 094916-1-094916-7 (2008)

21. Sun, J., Guo, Y.B.: A comprehensive experimental study on surface integrity by end milling Ti-6Al-4V. J. Mater. Process. Technol. 209, 4036-4042 (2009)

22. Che-Haron, C.H., Jawaid, A.: The effect of machining on surface integrity of titanium. J. Mater. Process. Technol. 166, 188-192 (2005)

23. Dryzek, J., Kozłowska, A.: Recrystallization in subsurface zone seen by positron annihilation. Tribol. Int. 43, 447-454 (2010)

24. Dryzek, J.: Positron annihilation studies of recrystallization in the subsurface zone induced by friction in magnesium - effect of the inhomogeneity on measured positron annihilation characteristics. Appl. Phys. A 114, 465-467 (2014) 